\title{
Percutaneous endoscopic removal of a biliary metal stent retained in the jejunum using a digital cholangioscope
}

Temporary placement of a biliary metal stent is a useful percutaneous treatment for benign hepaticojejunal anastomotic stricture [1-4]. However, a metal stent that has been placed will sometimes migrate spontaneously and can be retained in the jejunum. Endoscopic removal of a migrated metal stent retained in the jejunum is sometimes technically challenging and, in difficult cases, invasive surgical removal is required. Here, we describe the successful non-invasive endoscopic removal of a retained metal stent using a digital cholangioscope that was passed via the percutaneous fistula created by a percutaneous transhepatic biliary drain. A 70-year-old man with a surgical hepaticojejunostomy had suffered from recurrent cholangitis due to hepaticojejunal anastomotic stricture. As an endoscopic approach to the anastomosis using a balloon enteroscope failed because of severe adhesions, percutaneous transhepatic biliary drainage was performed; however, frequent drainage catheter replacement was required. A fully covered biliary metal stent with a lasso (HANAROSTENT Biliary; Boston Scientific Corp.) was therefore placed at the anastomosis via the percutaneous fistula ( Fig.1). The metal stent spontaneously migrated several days later and was retained in a sharp bend in the jejunum near to the anastomosis for 4 months, although the anastomotic stricture had improved (-Fig.2). The patient refused surgical removal of the stent, so endoscopic removal via the percutaneous fistula using a digital cholangioscope was attempted ( $>$ Video 1).

First, a 0.025 -inch guidewire was placed near the retained metal stent. A digital cholangioscope (SpyGlass DS System;
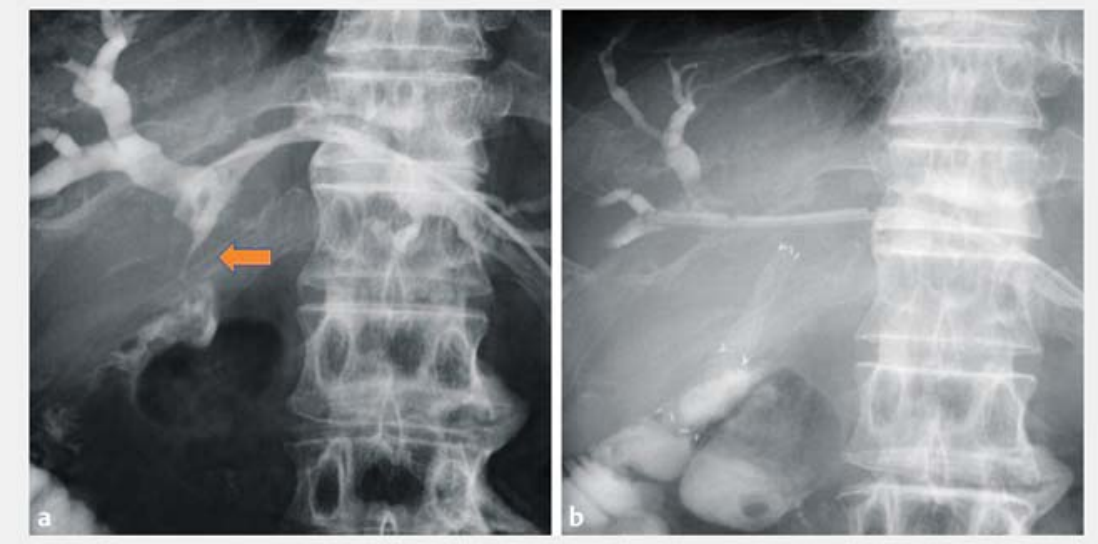

- Fig. 1 Radiographic images of the percutaneous temporary metal stent placement showing: $\mathbf{a}$ the severe hepaticojejunal anastomotic stricture (arrow); $\mathbf{b}$ a fully covered biliary metal stent with a lasso in position at the anastomosis.

Boston Scientific Corp.) was then inserted using guidewire guidance into the jejunum through the hepaticojejunal anastomosis via the percutaneous fistula. The lasso of the metal stent was grasped with a biopsy forceps under direct visualization and was retracted into the cholangioscope. The cholangioscope was gradually pulled out through the intrahepatic bile duct and the retained metal stent was successfully removed via the percutaneous fistula. This technique is a useful and non-invasive option for removal of a retained stent.

Endoscopy_UCTN_Code_CPL_1AK_2AD

\section{Competing interests}

T. Itoi has received speaker's fees from Boston Scientific Japan. The remaining authors declare that they have no conflict of interest.

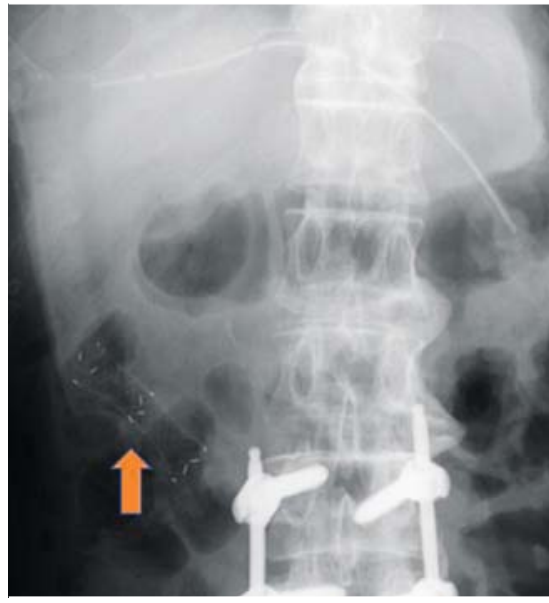

- Fig. 2 Radiographic image showing the metal stent (arrow) that had spontaneously migrated 4 months previously and was retained in the jejunum. 


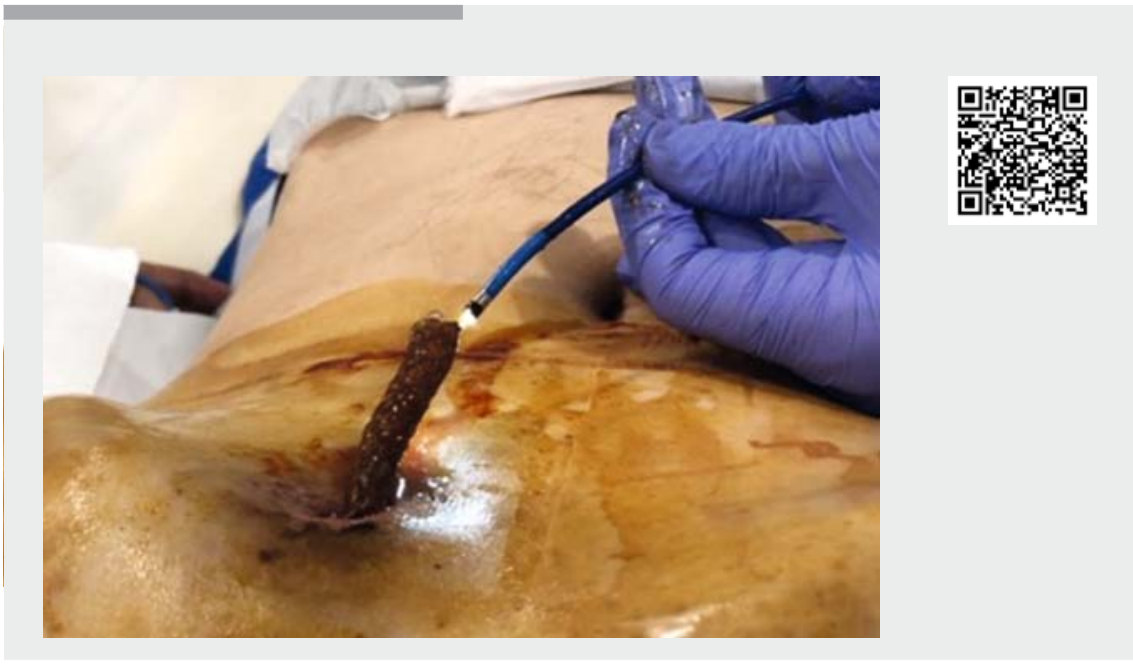

Video 1 Endoscopic removal of a biliary metal stent retained in the jejunum was performed using a digital cholangioscope via the percutaneous fistula.

\section{The authors}

Shuntaro Mukai, Takao Itoi, Atsushi Sofuni, Takayoshi Tsuchiya, Kentaro Ishii, Reina Tanaka, Ryosuke Tonozuka

Department of Gastroenterology and Hepatology, Tokyo Medical University, Tokyo, Japan

\section{Corresponding author}

\section{Takao Itoi, MD, PhD}

Department of Gastroenterology and Hepatology, Tokyo Medical University, 6-7-1 Nishishinjuku, Shinjuku-ku, Tokyo 160-0023, Japan Fax: +81-3-53816654 itoi@tokyo-med.ac.jp

\section{Bibliography}

Endoscopy 2021; 53: E201-E202

DOI 10.1055/a-1234-6062

ISSN 0013-726X

published online 11.9.2020

(c) 2020. Thieme. All rights reserved.

Georg Thieme Verlag KG, Rüdigerstraße 14,

70469 Stuttgart, Germany

\section{ENDOSCOPY E-VIDEOS}

https://eref.thieme.de/e-videos

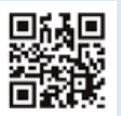

Endoscopy E-Videos is a free access online section, reporting on interesting cases and new

techniques in gastroenterological endoscopy. All papers include a high quality video and all contributions are freely accessible online.

This section has its own submission website at

https://mc.manuscriptcentral.com/e-videos 